\title{
Blockchain is Boundless and Exciting, but we Have to Keep Both Feet on the Ground
}

\author{
Jan Veuger* \\ Professor Block Chain Saxion University of Applied Sciences, Netherlands
}

ISSN: 2576-8840

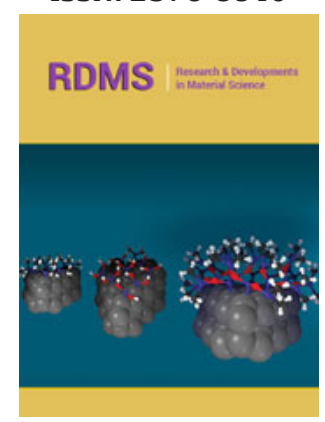

*Corresponding author: Jan Veuger, Professor Block Chain Saxion University of Applied Sciences, Netherlands

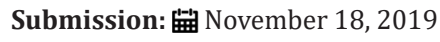

Published: :

Volume 12 - Issue 3

How to cite this article: Jan Veuger. Blockchain is Boundless and Exciting, but we Have to Keep Both Feet on the Ground. Res Dev Material Sci. 12(3). RDMS.000787.2019.

DOI: 10.31031/RDMS.2019.12.000787

Copyright@ Jan Veuger, This article is distributed under the terms of the Creative Commons Attribution 4.0 International License, which permits unrestricted use and redistribution provided that the original author and source are credited.

\section{Opinion}

Now that Blockchain is gaining more and more ground in a large number of sectors, the need for scientific research into this technology and its applications is also growing. Not only to map facts, developments and prognoses, but also to continue to interpret and discuss the phenomenon in the right way. I wrote the book 'Blockchain Technology and Applications': The discussion about Blockchain is clouded by fear rhetoric. We just have to keep talking about the facts.

At the end of last year, the national newspaper de Volkskrant in the Netherlands hinted at the demise of the Blockchain hype. That article triggered me. When I looked into it, I discovered that the article was based on only two sources: an A4 sheet of paper from a consultancy firm and a source about which the journalist in question did not want to give me any clarity. In my opinion, the piece is characteristic of the current unintended discussion about Blockchain, partly based on disbelief it won't go that fast and partly on inconvenience as long as Blockchain doesn't kill my business.

For the past two years I have been doing scientific research with his lectorate on the way Blockchain developed. As a lectorate of a University of Applied Sciences, we are, of course, mainly engaged in applied research, together with students. In addition, we do build a bridge to scientific research. As a lecturer, I want to fulfil the pivotal function between the two domains. That is exactly what I want to achieve with this book. We make fundamental Blockchain research transparent: how it can be done, how it works and what you have to do with it. As a research group, we want to stick to the facts, in order to counterbalance stories from the media, politics and the business world, which are sometimes on the receiving end of quicksand. Wildwest stories are fun for a birthday, but no more than that.

For example, the current discussion about cryptomunt libra is quite politically driven. The digital Facebook coin evokes social discomfort, a feeling that obviously does not come out of the blue, given the data scandals in which Facebook has been involved in recent years. We are afraid that our libra payment traffic will be traded by Facebook, together with our data. We are afraid that it will become clear what we spend our libras on. This fear may not be unfounded, but it does not in fact differ from other privacy discussions about payment transactions. Moreover, when Donald Trump claims that cryptocurrency is being used to finance terrorist or other illegal transactions on a large scale, the American president ignores how his own dollar is being misused. For example, in the funding of weapons or drugs. The discussion is therefore not being conducted purely and simply.

Digital coins are common, no matter what governments or banks may think of them. And there are more and more of them. Besides the libra and the bitcoin, there are many others. In the European banking sector, a qualitative discussion about crypto coins is now taking place. Banks don't like it, so to speak. Of course, that's not crazy. They are directly affected by these new possibilities. The consumer will soon be able to get around them. The banking sector fears part of its right to exist. Nobody can predict exactly how Blockchain technology will become established in all kinds of sectors, including the banking sector, in the coming years. It is a fact that things are going to change. 
This year, the International Monetary Fund published a report in which director Christine Lagarde outlines various scenarios. The most conservative prognosis is that the banks will continue to function normally. It is also conceivable that a hybrid situation could arise. Or that, in the most extreme case, there will no longer be any banks in several years time. Whatever scenario comes true and at what pace these developments will follow each other: the banks will have to take a stand, formulate policy and anticipate what is to come. It is not so much the question of technology how we are going to regulate it but rather the question of power who is allowed to regulate it that plays a role here. It's all about governance. Who has the power to decide whether or not to print money? Who decides whether interest rates will fall?

This question of power does not, of course, only concern the monetary system. What about institutions that see their unique land ownership services overtaken by Blockchain technology? We have a very good Land Registry in the Netherlands, but if you have received a piece of land from your grandfather in Africa, how can you prove that it is yours? You don't have an ID certificate, you don't have a bank, but you do have a mobile phone. Then Blockchain is a solution to unambiguously arrange and register properties. By the way, I see that a body like Het Kadaster is also working on a Blockchain, low profile. What is well organized in so many places in the Netherlands can be enhanced and secured with this technology. So, you end up in those hybrid constructions that the IMF was referring to.

I see a cautious but constructive attitude towards Blockchain emerging among European governments. In Germany and Switzerland, we see that governments are developing a vision and are therefore partly preoccupied with amending legislation. Here in the Netherlands, people are cautious, but not cramped. Various ministries are giving their light to experts who are asking for explicit advice from institutions such as Saxion and the University of Tilburg. It is good that we remain critical, ask the right questions about supervision, legislation and regulations, and above all continue to look ahead. That is also what we do as a research group.

With our book we want to provide insight into what is happening around Blockchain. It's all about mapping out this relatively young phenomenon. This scientific blueprint remains of value, even though the technology is developing rapidly. Leonardo da Vinci's drawings and calculations of his attempts to fly also remain interesting, although we are capable of so much more in this century. That's how you should see this first publication. Libraries are full of information about the economic developments of the past century. Blockchain is about a new economy. One that revolves around networking. The technology is boundless and therefore also exciting. This requires research that enables us to keep both feet on the ground and to have the right discussions.

The book 'Blockchain Technology and Applications', edited by Jan Veuger, was published by Nova Science Publishers. The second part is expected to be published in the first half of 2020. In November 2019, Arthur Janse and Chhay Lin Lim, both lecturers and researchers at the Blockchain professorship of Saxion University of Applied Sciences, published the 'Basic Book Blockchain'. An English version of the basic book will be published in the course of 2020 . The book forms the basis for a public digital knowledge platform that will also be launched in the course of 2020 .

With thanks to Anne Hurenkamp, writer and information specialist at Saxion University of Applied Sciences and freelance writer for the support and cooperation on this article. 